\title{
Splice Testing for LHC Quadrupole Magnets
}

\author{
E. Barzi, R. Bossert, S. Feher, J. Kerby, V. V. Kashikhin, M. J. Lamm, D. Orris, G. Ray, M. Tartaglia, and A. V. Zlobin
}

\begin{abstract}
Electrical splices between NbTi Rutherford type cables need to be made for the LHC IR inner triplet quadrupoles. Splices between magnets as well as internal to the magnets are necessary. Various splice configurations, solders, and fluxes have been considered. Testing of these splices at cryogenic temperatures and at various currents has been completed. The results were satisfactory; Fermilab is capable of making excellent low resistance $(<\mathbf{n} \Omega)$ solder joints for the LHC project.
\end{abstract}

Index Terms-Solder joints, splice, superconducting magnets.

\section{INTRODUCTION}

$\mathbf{T}$ HE FINAL focus triplets in the interaction regions at the Large Hadron Collider (LHC) require high gradient quadrupoles. Each triplet consists of four quadrupoles with $70 \mathrm{~mm}$ bore and peak operating field gradients of $215 \mathrm{~T} / \mathrm{m}$. Fermilab is providing half of the Interaction Region inner triplet quadrupoles and KEK the other half. Fermilab will do the final assembly and cryostating of all magnets.

Fabrication of the quadrupoles and installing them into the LHC tunnel requires splicing together superconducting cables. To develop the design and fabrication procedures for reproducible manufacturing of superconducting magnets, a $2 \mathrm{~m}$ model-magnet program was started in 1997 and successfully completed in 2000 [1]. As part of this program several splice tests were performed to validate the splice design and the splicing technique originally developed for the Tevatron.

This paper summarizes the test results of these splice measurements.

\section{Splice Design and Resistance Calculation}

Under high DC and AC current operation, soldered cable joints will generate heat due to their finite resistance and eddy current losses at the spliced area. The larger the spliced area, the lower is the resistance of the splice. On the other hand AC losses are inversely proportional to the splice area.

It has been shown that a $120 \mathrm{~mm}$ long splice area is short enough to keep eddy current losses within an acceptable limit even if the splices are located in a relatively high magnetic field region. It was also shown that when the magnet joint resistances are kept around $1 \mathrm{n} \Omega$, the magnet would not suffer any performance degradation [2].

In order to estimate the splice resistance from the conductivity of the solder and the copper matrix of the strands several splices

Manuscript received August 6, 2002. This work was supported by the U.S. Department of Energy.

The majority of the authors are with Fermi National Accelerator Laboratory.

G. Ray was summer student at Fermilab at the time the splice measurements were taken.

Digital Object Identifier 10.1109/TASC.2003.812654

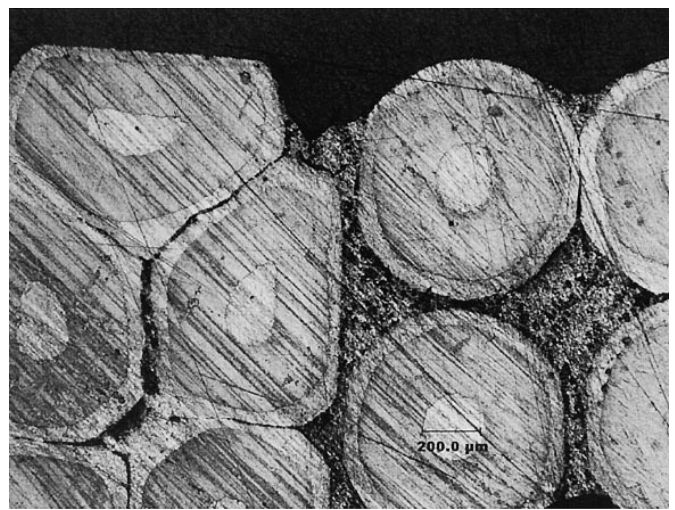

Fig. 1. LHC inner cable to LHC inner cable splice cross section.

were sliced and polished. Using a microscope we were able to distinguish between the solder and the boundary of the strand (see Fig. 1). Since the solder resistivity in general is several orders of magnitude larger than that of the copper, the strands can be treated as equipotentials. A further reasonable approximation is to assume that the crossing current flows in straight lines perpendicular to the lap joint. With these assumptions, we may calculate the joint resistance as the summation of parallel current paths. The splice resistance dominated by the solder layer between the two cables can be estimated as:

$$
\frac{1}{R_{\text {splice }}^{\text {layer }}}=\frac{L}{\rho} \sum_{i} \frac{\Delta a_{i}}{d_{i}}
$$

where $L$ is the length of the splice, $\rho$ is the resistivity of the solder, $\Delta a$ is a distance segment (used for the computation) along the width of the cable and $d$ is the distance across the solder between the strands. Obviously $\Delta a$ should be chosen to be small enough that $d$ is approximately constant along $\Delta a$. In order to estimate the total resistance of the splice the resistance of the second layer should be added in parallel with the first one. Since from the second layer the current has to pass three times as much solder as the first layer, plus it has to go through the copper matrix of the strands of the first layer, the total resistance of the splice will be reduced by $10 \%$ relative to the first layer resistance.

The resistances were calculated for two types of splices: i), the splice between FNAL/LHC inner to FNAL/LHC inner cable; and ii), the splice between FNAL/LHC inner to FNAL/LHC outer cable. Using $\rho=7.4 \times 10^{-9} \Omega \mathrm{m}$ for $70 / 30$ $\mathrm{Pb} / \mathrm{Sn}$ solder [3] and $\rho=1.69 \times 10^{-10} \Omega \mathrm{m}$ for the copper matrix resistivity (at $4.5 \mathrm{~K}$ ) within the strand, we obtained i), $0.22 \mathrm{n} \Omega$; and ii), $0.18 \mathrm{n} \Omega$ values. Due to the low resistivity value of the copper matrix its contribution to the total resistance is $\sim 5 \%$. 
TABLE I

CABLE PARAMETERS

\begin{tabular}{lcccc}
\hline \hline Cable Type & $\begin{array}{c}\text { Strand } \\
\text { diameter }\end{array}$ & $\begin{array}{c}\text { Cable width/ } \\
\text { mid thickness }\end{array}$ & $\begin{array}{c}\text { Number } \\
\text { of strands }\end{array}$ & Twist pitch \\
\hline FNAL Inner & $0.808 \mathrm{~mm}$ & $15.4 / 1.45 \mathrm{~mm}$ & 37 & $114 \mathrm{~mm}$ \\
FNAL Outer & $0.648 \mathrm{~mm}$ & $15.4 / 1.15 \mathrm{~mm}$ & 46 & $102 \mathrm{~mm}$ \\
KEK Inner & $1.065 \mathrm{~mm}$ & $15.0 / 1.89 \mathrm{~mm}$ & 28 & $110 \mathrm{~mm}$ \\
\hline \hline
\end{tabular}
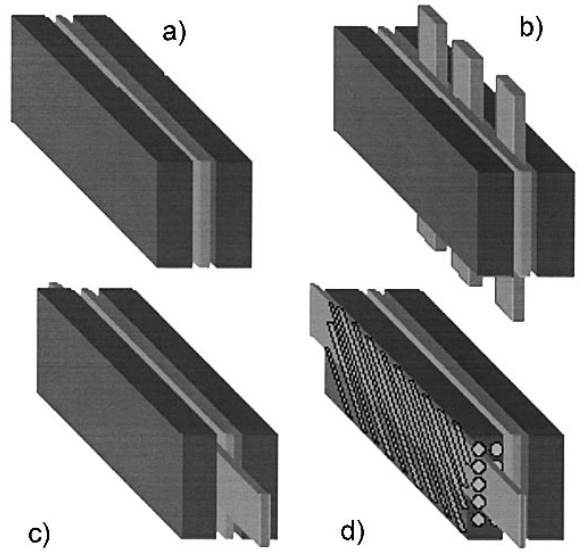

Fig. 2. Schematics of the different type of solder joints are shown. The standard solder joint is made by placing solder strip between the cables (a). Kapton film was placed vertically (b) and horizontally (c) between the cables to reduce the area of the splice. Kapton film was placed in between the cable itself to check the effect of the solder penetration inside the cable (d).

\section{SPlice MEASUREMENTS}

\section{A. Sample Preparation}

The superconducting cables used in this study are described in Table I. After the cable was cleaned with Scotchbrite and alcohol the spliced area was pre-tinned or filled with solder before the splice took place. During pre-tinning, solder was applied with a soldering iron using solder wire anywhere from $0.75 \mathrm{~mm}$ to $3 \mathrm{~mm}$ in diameter.

Most of the splices were made by placing a strip of solder between the cable pairs that were soldered. The strip was manufactured specifically for this application, and was either 0.12 $\mathrm{mm}$ or $0.25 \mathrm{~mm}$ thick by $15 \mathrm{~mm}$ wide. The spliced area was placed into a fixture, which had a cavity machined to the size of the splice cross section. The fixture was bolted together using shoulder screws with die springs to provide a uniform clamping force. The applied pressure was approximately $3.5 \mathrm{MPa}$ (500 PSI). Electric cartridge heaters inserted into holes in the fixture provided heat. When the heaters were turned on the temperature of the soldered area was monitored with a thermocouple. The heater cartridge was turned off when the solder melted, which was visually observable. After cooling, the splice was removed from the fixture and the exterior was cleaned with Scotchbrite.

Four batches (16 splices per batch) of splices were made and tested. The primary goal for the first batch was to check the splice quality as a function of the amount of the spliced area. Samples with Kapton films inside or between the cables were used to model the effect of the solder penetration inside the cable or to reduce the splice area by a controlled amount. The schematics of these different types of solder joints are shown in Fig. 2.
TABLE II

SPLICE SAMPLES

\begin{tabular}{lcccccc}
\hline \hline $\begin{array}{l}\text { Joint } \\
\text { Type }\end{array}$ & $\begin{array}{c}\text { 1st } \\
\text { Cable }\end{array}$ & $\begin{array}{c}\text { 2nd } \\
\text { Cable }\end{array}$ & $\begin{array}{c}\text { Solder } \\
\text { Type }\end{array}$ & $\begin{array}{c}\text { Kapton } \\
\text { Coverage }\end{array}$ & $\begin{array}{c}\text { Solder } \\
\text { Strip }\end{array}$ & $\begin{array}{c}\text { No of } \\
\text { Samples }\end{array}$ \\
\hline J1 & C1 & C3 & S1 & - & $0.12 \mathrm{~mm}$ & 6 \\
J2 & C1 & C3 & S1 & KH & $0.12 \mathrm{~mm}$ & 2 \\
J3 & C1 & C3 & S1 & KV & $0.12 \mathrm{~mm}$ & 2 \\
J4 & C2 & C3 & S1 & - & $0.12 \mathrm{~mm}$ & 9 \\
J5 & C1 & C3 & S1 & K1 & $0.12 \mathrm{~mm}$ & 2 \\
J6 & C1 & C3 & S1 & K3 & $0.12 \mathrm{~mm}$ & 2 \\
J7 & C1 & C3 & S1 & K1,K3 & $0.12 \mathrm{~mm}$ & 2 \\
J8 & C1 & C3 & S1 & - & - & 2 \\
J9 & C3 & C3 & S1 & - & $0.12 \mathrm{~mm}$ & 2 \\
J10 & C1 & C1 & S1 & - & $0.12 \mathrm{~mm}$ & 2 \\
J11 & C2 & C2 & S2 & - & $0.25 \mathrm{~mm}$ & 4 \\
J12 & C2 & C3 & S2 & - & $0.25 \mathrm{~mm}$ & 8 \\
J13 & C3 & C3 & S2 & - & $0.25 \mathrm{~mm}$ & 5 \\
J14 & C2 & C4 & S3 & - & $0.25 \mathrm{~mm}$ & 10 \\
J15 ${ }^{\text {a }}$ & C2 & C2 & S3 & - & $0.25 \mathrm{~mm}$ & 4 \\
\hline
\end{tabular}

C1 - FNA:/LHC Inner left lay cable

C2 - FNAL/LHC Inner right lay cable

C3 - FNAL/LHC Outer left lay cable

$\mathrm{C} 4-\mathrm{KEK} / \mathrm{LHC}$ Inner right lay cable

$\mathrm{S} 1$ - Lead tin solder $\mathrm{Pb}(70 \%) \mathrm{Sn}(30 \%)$ using Kester 1544 Flux

S2 - Tin Silver solder $\operatorname{Sn}(95 \%) \operatorname{Ag}(5 \%)$ using Kester 135 Flux

S3 - Tin Silver solder Sn(96\%)Ag(4\%) using Kester 135 Flux

$\mathrm{KH}(\mathrm{V})$ - Kapton was placed horizontally (vertically) between the two cable covering $50 \%$ of the spliced area

$\mathrm{K} 1$ - Kapton was placed inside $\mathrm{C} 1$ providing $50 \%$ coverage

$\mathrm{K} 3$ - Kapton was placed inside $\mathrm{C} 3$ providing $50 \%$ coverage

${ }^{a}$ Additional pure copper cable was placed in between the supeconducting cables

Since the outer and inner cable is different we also checked the affect of the different cable combinations used to make the splices. The reason for the second batch was to obtain more data on the standard LHC quadrupole splices. For the first two batches we used 70/30 Pb/Sn solder and Kester 1544 flux which was the solder type used in the High Gradient Quadrupole R\&D program.

Early in the long magnet production process, discussions with CERN revealed that the solder to be used in the interconnect area at the LHC was $96 / 4 \mathrm{Sn} / \mathrm{Ag}$. In addition, the small amount of chloride $(0.44 \%)$ contained in the Kester 1544 flux was undesirable, due to the possible corrosive effect on stainless steel. As a result, Fermilab switched to the $96 / 4 \mathrm{Sn} / \mathrm{Ag}$ solder with Kester 135 flux for the production program to avoid contamination of CERN joints with the FNAL material and to eliminate the chloride. The third batch of splices was done primarily to validate the soldering techniques described above using the $\mathrm{Sn} / \mathrm{Ag}$ with Kester 135 combination. Both 95/5 Sn/Ag and 96/4 Sn/Ag are used and treated identically for these tests due to their similarity.

The size of the cable used by KEK to build quadrupoles for the LHC is different from the one Fermilab is using. The fourth batch of splices was made by using KEK and Fermilab type of cable joints. Table II contains the description of all the different types of splices that were tested and Fig. 3. shows the cross section of three different types of splice samples.

\section{B. Test Setup}

In order to test sixteen splices at once a special fixture was developed shown in Fig. 4. The splices were kept rigidly supported between G10 plates. Grooves were also introduced to provide cooling channels for the splices. 


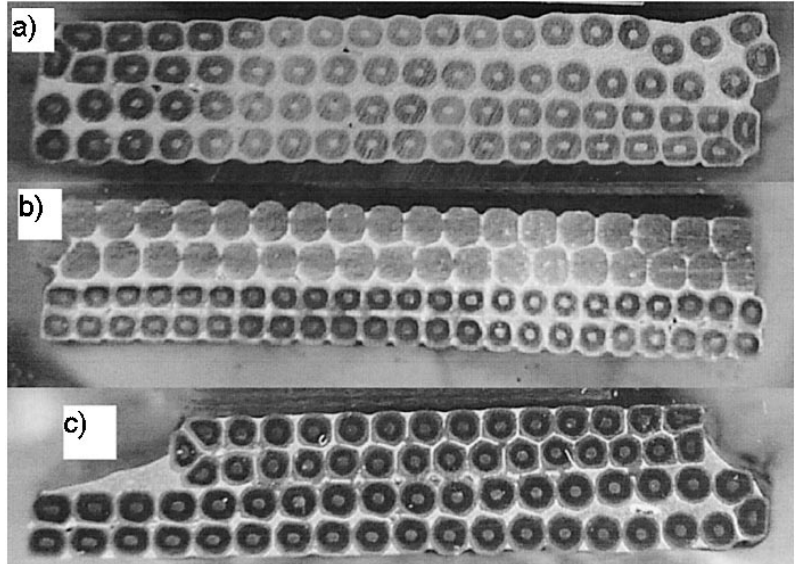

Fig. 3. Splice cross sections: (a) Fermilab inner cable to Fermilab inner cable splice; (b) Fermilab inner cable to Fermilab outer cable; (c) Fermilab inner cable to KEK inner cable.

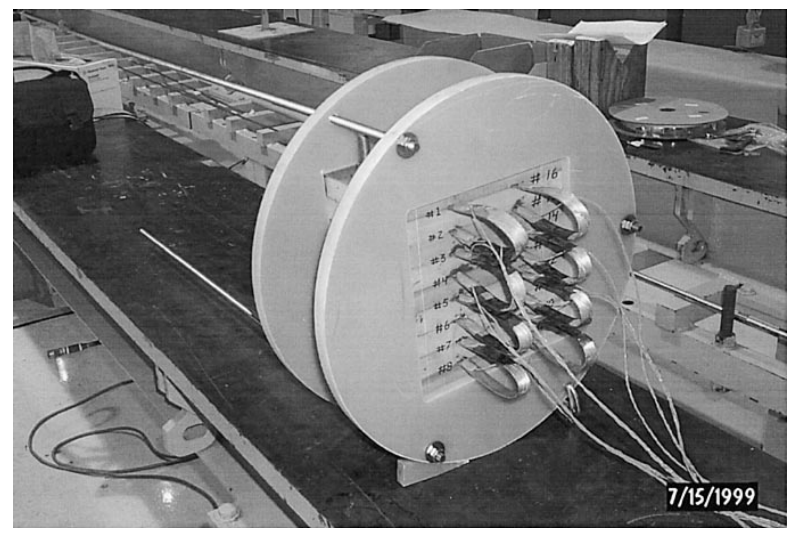

Fig. 4. Typical splice measurement using two different type of solder.

The test was performed at the Fermilab Magnet Test Facility using test Stand 3 [4], which was primarily developed for testing HTS power leads. This stand was capable of conducting current up to $5000 \mathrm{~A}$ and cooling the samples down to $4.3 \mathrm{~K}$. The voltages across the splices were measured with an HP3158A DMM. The current was increased in stair steps of $500 \mathrm{~A}$ up to $5000 \mathrm{~A}$ and back down to $0 \mathrm{~A}$. Each reading was taken by applying a 40 line-cycle integration time to reduce noise.

\section{Test Results}

Typical measurements of splice measurements vs. current are plotted in Fig. 5. The 70/30 Pb/Sn solder is a weak type II superconductor. We performed magnetization measurements and obtained $\mathrm{B}_{c 1}(4.2 \mathrm{~K})=88 \mathrm{mT}$ and for $B_{c 2}(4.2 \mathrm{~K})=132 \mathrm{mT}$ values. Since the peak self field at the splice area is $\sim 50 \mathrm{mT} / \mathrm{kA}$ the splice resistance up to few $\mathrm{kA}$ will be dominated by the copper resistance of the strands, which, as we have seen earlier, is very low $\sim 0.01 \mathrm{n} \Omega$. In order to predict the splice resistance change as a function of current we need to know the value of $J_{c}$ of the solder as a function of the magnetic field. On the other hand, the splice resistance is not changing rapidly around 5000 A indicating that the solder at this current (and higher) becomes normal. Splice resistance values reported in this paper for lead-tin solder joints were measured at $5000 \mathrm{~A}$.

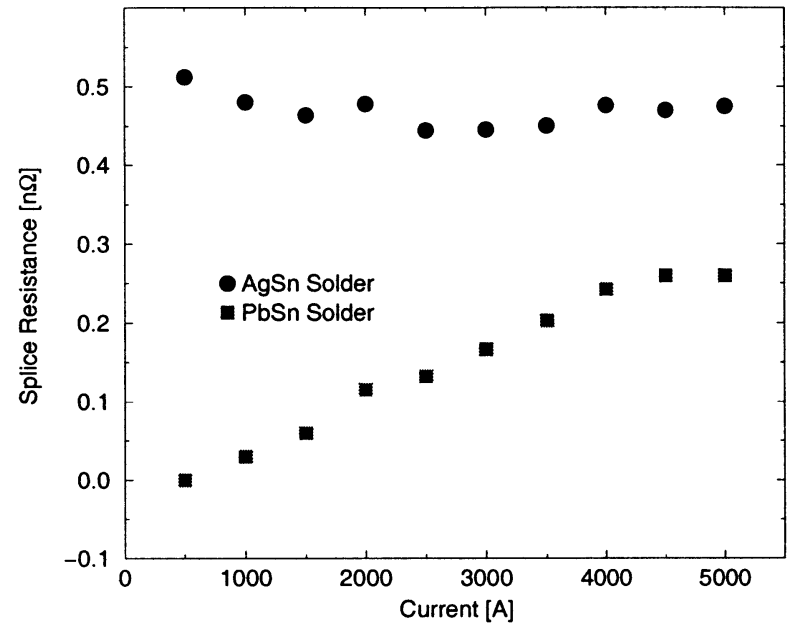

Fig. 5. Typical splice measurement using two different type of solder.

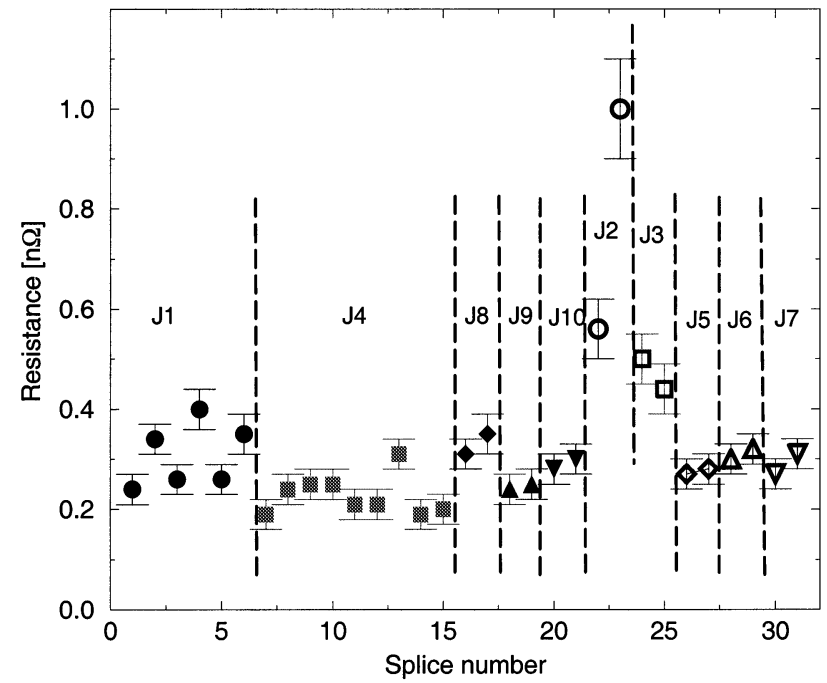

Fig. 6. Splice resistance measurements for splices made with lead-tin solder. $\mathrm{J} 1, \ldots, \mathrm{J} 10$ are the notations of the different type of solder joints described in Table I.

The measured splice resistance values are presented in Fig. 6, Fig. 7, and in Table III. All of the measured splice resistance values are $\leq 1 \mathrm{n} \Omega$ except those solder joints where copper cable was inserted between the two superconducting cables (J15). In that case the increase in resistance was about a factor of three. However, this was expected since the solder thickness between the superconducting cables due to a two layer copper cable was increased by a factor of three.

In Fig. 6, J1, J4, J8, J9 and J10 sample resistances are quite similar. Since these samples only differ from each other by the cable type we can conclude that the splice resistance does not have a strong dependence on the type of LHC cable used to make the splices.

The splice resistance of samples J2 and J3, which had half of their splice area covered with Kapton tape increased by a factor of two. These samples demonstrate the importance of the solder penetration between the cables. On the other hand, no noticeable change of the resistances was observable by placing Kapton tape inside the cable (J5, J6, J7 samples). This is again in good agreement with expectations since the contribution of 


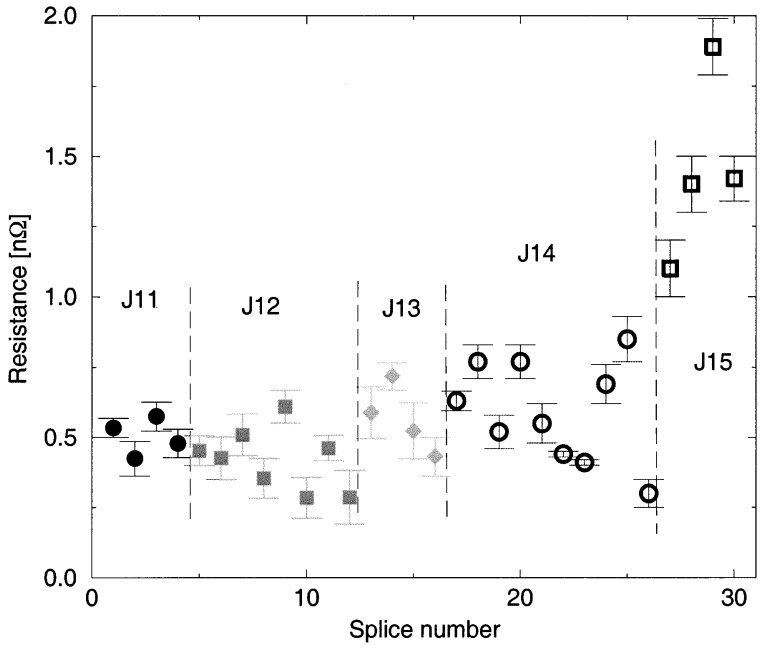

Fig. 7. Splice resistance measurements for splices made with tin-silver solder. $\mathrm{J} 11, \ldots, \mathrm{J} 15$ are the notations of the different type of solder joints described in Table I.

TABLE III

SPLICE MEASUREMENTS

\begin{tabular}{lccccccc}
\hline \hline J1 & J2 & J3 & J4 & J5 & J6 & J7 & J8 \\
\hline 0.24 & 0.56 & 0.50 & 0.19 & 0.27 & 0.30 & 0.27 & 0.31 \\
0.34 & 1.00 & 0.44 & 0.24 & 0.28 & 0.32 & 0.31 & 0.35 \\
0.26 & & & 0.25 & & & & \\
0.40 & & & 0.25 & & & & \\
0.26 & & & 0.21 & & & & \\
0.35 & & & 0.21 & & & & \\
& & & 0.31 & & & & \\
& & & 0.19 & & & & \\
\hline J9 & J10 & J11 & J12 & J13 & J14 & J15 & \\
\hline 0.24 & 0.28 & 0.53 & 0.45 & 0.59 & 0.63 & 1.10 & \\
0.25 & 0.30 & 0.42 & 0.43 & 0.72 & 0.77 & 1.40 & \\
& & 0.57 & 0.51 & 0.52 & 0.52 & 1.89 & \\
& & 0.48 & 0.35 & 0.43 & 0.77 & 1.42 & \\
& & & 0.61 & & 0.55 & & \\
& & & 0.46 & & 0.44 & & \\
& & & 0.28 & & 0.41 & & \\
& & & & & 0.65 & & \\
& & & & & 0.69 & & \\
\hline \hline
\end{tabular}

The splice resistance values are in $\mathrm{n} \Omega$

The error of the measurements was $\sim \pm 10 \%$ the second layer to the total resistance is small so we can conclude that solder penetration inside each cable doesn't have a significant effect on the quality of the solder joint.

The average measured resistance value for the lead tin solder was $0.27 \mathrm{n} \Omega$, which is about $25 \%$ higher than the predicted resistance $(\sim 0.2 \mathrm{n} \Omega)$. It is also noticeable that there is a wide spread of the resistances. This might be related to the splicing technique, which can produce irregular solder coverage or change of the solder resistivity.

In Fig. 7 it is also noticeable that the cable type doesn't have a strong effect on the splice resistance. However, the average resistance value of the $\mathrm{J} 14$ sample is about $30 \%$ higher than that of the J11, J12 and J13 samples. The KEK cable is narrower than the Fermilab cable by the same amount, by $\sim 30 \%$, which explains the difference.

\section{CONCLUSION}

A variety of splices were tested at Fermilab to validate the splice design and manufacturing technique. Using the soldering procedure developed, we can systematically produce splices with less than $1 \mathrm{n} \Omega$ resistance values. The average splice resistance value is in good agreement with prediction. We have also demonstrated that the CERN recommended AgSn solder can be used for the USLHC magnet program.

\section{ACKNOWLEDGMENT}

The authors thank the staff of Fermilab's Technical Division who have worked so hard on the effort of producing excellent superconducting magnets over the course of the past few years.

\section{REFERENCES}

[1] N. Andreev et al., "Status of the LHC inner triplet quadrupole program at Fermilab," IEEE Transactions on Applied Superconductivity, vol. 11, no. 1, p. 1558, March 2001.

[2] A. Zlobin, "Unpublished note,", 1997.

[3] J. R. W. Fast, "Electrical and mechanical properties of lead/tin solders and splices for superconducting cables," Cryogenics, vol. 28, pp. 7-9, Jan. 1988.

[4] G. Citver et al., "HTS power lead test results," in Proc. Of the 1999 Particle Accelerator Conf., New York, 1999, pp. 1420-1422. 